\title{
The Relation between Skills of Coping Strategy and Lateralization among Students
}

\author{
Akram Malekzadeh \\ Department of Educational Sciences and Psychology, Payame Noor University (PNU), pobox 19395-3697, Tehran, IR of Iran
}

Doi:10.5901/mjss.2015.v6n6s6p424

\section{Abstract}

The process of lateralization and the difference between the left hand and right-handers is one of the issues, which attracted many researchers' attention. One of the interesting and important issues which are studied less is the coping strategy. This study aims to contrast the coping strategy in the right and left-handers. For this purpose, 60 individuals (30 the left handed and 30 the right-handed) are chosen. Also, there are 15 males and 15 females in each group. Edinberg's handedness inventory is used in order to investigate the extent to which lateralization happens. Furthermore, in order to investigate coping strategy, Lazarus' coping strategy is used. The data are analyzed by the amount of variance. The findings of the study illustrates that the left-handers use appraisal focused strategies while the right-handers use the emotion- focused one. These relations are statistically meaningful. In direct coping strategy, the mean for the left-handers is higher but this kind of relation is not statistically meaningful. In distance strategy, the mean for the right-handed females is higher than that for the left-handed females while the mean for the left-handed males is higher than that for the right hand ones but this kind of relation is not statically meaningful. In self-control strategy, the mean for the left handed in both genders is higher but this kind of relation is not statically significant. In searching for social support strategy, the mean for the lefthanders in both genders is higher and also this kind of relation is statistically significant. In accepting responsibility strategy, the mean for the left-handed is higher in both genders; that is, this group uses the accepting responsibility strategy more and this kind of relation is statistically significant. In escape-avoidance strategy in both groups in terms of gender and left-handedness and right-handedness, no significant difference has been observed. In the problem solving strategy, the mean for the left-handed is higher in both genders. Of course, this kind of relation is not statistically significant.

Keywords: coping strategy, appraisal -focused strategy, emotion- focused strategy, lateralization, responsibility acceptance strategy, problem solving strategy, escape-avoidance strategy, self-control strategy, distance strategy, direct coping strategy

\section{Introduction}

Human's complex brain plays key role in human's procedures, functions and activities. Brain has two hemispheres. In most individuals, the left hemisphere controls human is action but, in rare cases, it is the right hemisphere, which is dominant. The dominance of one hemisphere to another is called lateralization. Brain lateralization can justify many of human's behaviors and activities and can justify changes in some of human's responses as well (Smart, 2012).

It is claimed that the left handed or right- hemisphere dominance has some pathologic reasons that can cause lack of development and decrease quality of life. In the first hand, it is said that the left handed, as a more fitness group, are less qualified than the right-handed. Being less qualified can be resulted largely from illnesses, side effects and events. Moreover, it can be a reason to predict that the left-handed are inefficiently qualified in terms of psychological experience or perhaps psychological qualification. In order to investigate this issue, a study was conducted in which 1277 subjects participated and four lists of lateralization dominance guide (hands, feet, eyes, and ears), the psychological health, psychological functions, stressful experiences and physical health were investigated. The study showed that just being left handed cannot predicate the decrease of life quality, and its respective factors but those subjects who tried to concealed their left handedness by using their right hand but were not successful in this respect, the quality of cognitive, psychological, and physical functions decreased (Porac \& Sealenman, 2003). The findings resulted from Regression and Variance in the study by Nettle (2003) showed that lateralization can influence psychological functions, talents and abilities.

The more brain is lateralized, the more influential its effects will be in the above mentioned issues. Of course, these studies illustrated that the left-handedness in the subjects with impulsive responses, hyperactivity, and smoking were higher (Smokler and Shevrin, 1979).

One of the psychological experiences with which human being confront is stress. The human being's ability in how to deal with problems and stresses play very important role in the individuals' psychological health and life quality. There are many factors which can influence these issues. Some of which are discovered by the psychologists and some others 
are rarely investigated due to their complexity (Booter, 2012).

The coping styles are the individuals' fixed characteristics. In the report of stress and the stressful situations, it was determined that the individuals responded automatically to the physical activities and behavioral responses in the stressful situations. It seems that the process of lateralization of brain and hemispheres is the influential factor in determining the way they were responded in these situations (Sullivan \& Gratton, 1998). These results can give us information concerning the coping skills. In the study in which the brain slides relating to the two groups, the left handed and right-handed together with different emotions were sent, the right hemisphere was active in absorbing the negative emotions while these activities were not observed in the left hemisphere when these emotions were sent.

Most of stresses are not controlled by us but can be caused by various changes in our behavior. These changes are resulted from the changes in brain chemistry. The brain system including cortex and prefrontal plays crucial role in this respect. The amount of balance in the brain is one of the factors mentioned in this respect and can be influential in the amount and method of coping with stresses. In another study, those rats who were under severe stress and their response were against the directions they chose to go and were not allowed to respond to the directions they intended to go they experienced more stresses (Carlson \& et.al, 1993).

In the study conducted on the rats, it was clarified that the increase and decrease of dopamine influenced the brain hemispheres differently. Dopamine attached to the left hemisphere. The brain imbalance and the dominance of one to another could be influential in organizing emotions and the psychological responses (Sullivan \& Gratton, 1998).

The dominance of the brain hemispheres and the amount of its imbalance play important role in responding to stresses, psychological behaviors, mental functions and human's high processes. In meta-analysis, it was illustrated that the method of responding, creative thought, analytical task, and figural task was closely related to the dominance of brain hemispheres (Mihor and et al., 2010). Moreover, it was shown that emotional intelligence, which was effective in the way it was responded to the environment, were closely related to brain hemisphere (Castro \&et al., 2010).

The brain lateralization can influence the psychological functions. In a study, it was shown that doing tasks could increase the blood flow operations in the dominant hemisphere (Nickolas \& et. al, 2012).

Considering the fact that the right-handedness can make noticeable some characteristics in the individuals especially in the left-handed who were labeled as minority. So, it is necessary that the researchers consider the different aspects of handedness and its respective factors (Hashimoto, et al., 2013). Although the role of brain system, lateralization and its interactions were investigated but its influence in the psychological behaviors and functions especially among students are needed to be investigated (Bibbey, 2013). Since the importance of this issue in this study, it is tried to contrast the left-handed students with the right-handed ones on the use of coping strategies.

\section{Methodology}

The study is a casual contrastive one by which the coping strategy and its subscales are investigated in the right handed and left-handed students. The population sample is 60 (30 female and 30 males) high school students. In each group, there are 15 right handed and 15 left-handed students. The measurement instruments are Lazaros and Folkman's coping strategy checklist that are designed in the software format. This test has 66 questions and numbered in 4 choices which are scaled from 1 to 4 and evaluate the two issues of appraisal- focused and emotion-focused status. Any of these appraisal-focused and emotion focused coping strategy paradigms are: confrontation: this method is a set of the aggressive behaviors used by the individuals in order to solve the problems and are entailed by some degrees of violence and risk taking in functions. Distancing: it shows a set of the psychological behaviors used by individual or group in order to avoid the source that causes the problem for the purpose of decreasing its importance. Self-esteem: this method is a set of reactions that include the individuals' emotional reactions when facing with the obstacle that makes the problem and avoid expressing such reaction by the individuals. Seeking the social support: it reinterprets the individuals' attempts to acquire the informative, tangible and emotional supports. Responsibility: this method includes a set of reactions that shows the individuals' capacity in making problems by his/ her continual attempts in order to review the present situation. Escape-avoidance: this method describes the wishful thoughts or behavioral attempts in order to escape or avoid situation that causes problems and includes avoiding reality. The planned problem solving: the set of correct and concentrated thoughts and attempts for facing with problems together with the use of the analytical approaches to solve the problem. The positive reevaluation: it refers to a set of the attempts that is used in order to make positive concepts with regard to the individuals' evolvement degree. This method may include the religious aspects. These octagonal paradigms are classified into two methods. The appraisal-focused methods (seeking social supports, responsibility, planned problem solving, and the positive reevaluation) and emotion- focused methods (confrontation, avoidance, escape-avoidance, self-esteem) (Esmaeili, 2008). The reliability of this test is calculated by the use of Cronbach's Alpha 
equaling to 0/79 (Lazaros, 1993). In this study, the reliability of the test is equal to 0/85 as well. The methodology used in this study is that the members of population samples are chosen among the high school females and males numbering 30 individuals, including 15 the left-handed and 15 the right-handed after determining the sample population. First, it is told to the subjects the importance and purpose of this study. Moreover, it is asked them to answer questions carefully.

\section{Findings}

In order to determine the relation between the handedness with each of these coping strategies with stress, mean and standard deviation of responses are determined in the group and the data are mentioned in the table. 1. Furthermore, concerning the independent variable and several dependent variables, the multivariate analysis of variance (MANOVA) is used and the data are mentioned in the table 2 and 3.

Table.1. Mean and standard deviation of the groups based on "coping Strategies" with an emphasis on "gender and handedness"

\begin{tabular}{|c|c|c|c|}
\hline Dependent variable & Gender and handedness & $M$ & SD \\
\hline \multirow{6}{*}{ Emotion-focused strategy } & Right handed females & 62.87 & 3.37 \\
\hline & Left handed females & 62.26 & 2.96 \\
\hline & Total & 62.55 & 3.12 \\
\hline & Right handed males & 66.43 & 6.02 \\
\hline & Left handed males & 53.15 & 8.89 \\
\hline & total & 60.48 & 9.92 \\
\hline \multirow{9}{*}{ Appraisal- focused strategy } & Right handed females & 31.14 & 13.99 \\
\hline & Left handed females & 38.93 & 10.34 \\
\hline & Total & 35.17 & 12.65 \\
\hline & Right handed males & 25.68 & 8.18 \\
\hline & Left handed males & 30.46 & 6.97 \\
\hline & Total & 27.82 & 7.91 \\
\hline & Total for the right handed & 28.23 & 11.40 \\
\hline & Total for the left handed & 35.0 & 9.77 \\
\hline & Total & 31.50 & 11.09 \\
\hline \multirow{6}{*}{ Coping strategy } & Right handed females & 16.78 & 0.89 \\
\hline & Left handed females & 17.13 & 0.91 \\
\hline & Total & 16.95 & 0.90 \\
\hline & Right handed males & 16.93 & 0.77 \\
\hline & Left handed males & 17.15 & 0.89 \\
\hline & Total & 17.03 & 0.82 \\
\hline \multirow{9}{*}{ Distancing strategy } & Right handed females & 16.90 & 0.91 \\
\hline & Left handed females & 16.60 & 1.05 \\
\hline & Total & 16.68 & 0.97 \\
\hline & Right handed males & 16.87 & 0.95 \\
\hline & Left handed males & 17.38 & 0.86 \\
\hline & Total & 17.10 & 0.93 \\
\hline & Total for the right handed & 16.80 & 0.92 \\
\hline & Total for the left handed & 16.96 & 1.03 \\
\hline & total & 16.87 & 0.97 \\
\hline \multirow{7}{*}{ Self-control strategy } & Right handed females & 16.0 & 1.51 \\
\hline & Left handed females & 18.06 & 1.27 \\
\hline & Total & 17.06 & 1.73 \\
\hline & Right handed females & 18.18 & 1.16 \\
\hline & Left handed females & 19.15 & 1.32 \\
\hline & Total & 18.62 & 1.32 \\
\hline & Total for the right handed & 18.62 & 1.32 \\
\hline \multirow{3}{*}{ Seeking social support } & Right handed females & 7.85 & 3.54 \\
\hline & Left handed females & 8.40 & 3.86 \\
\hline & Total & 8.13 & 3.66 \\
\hline
\end{tabular}




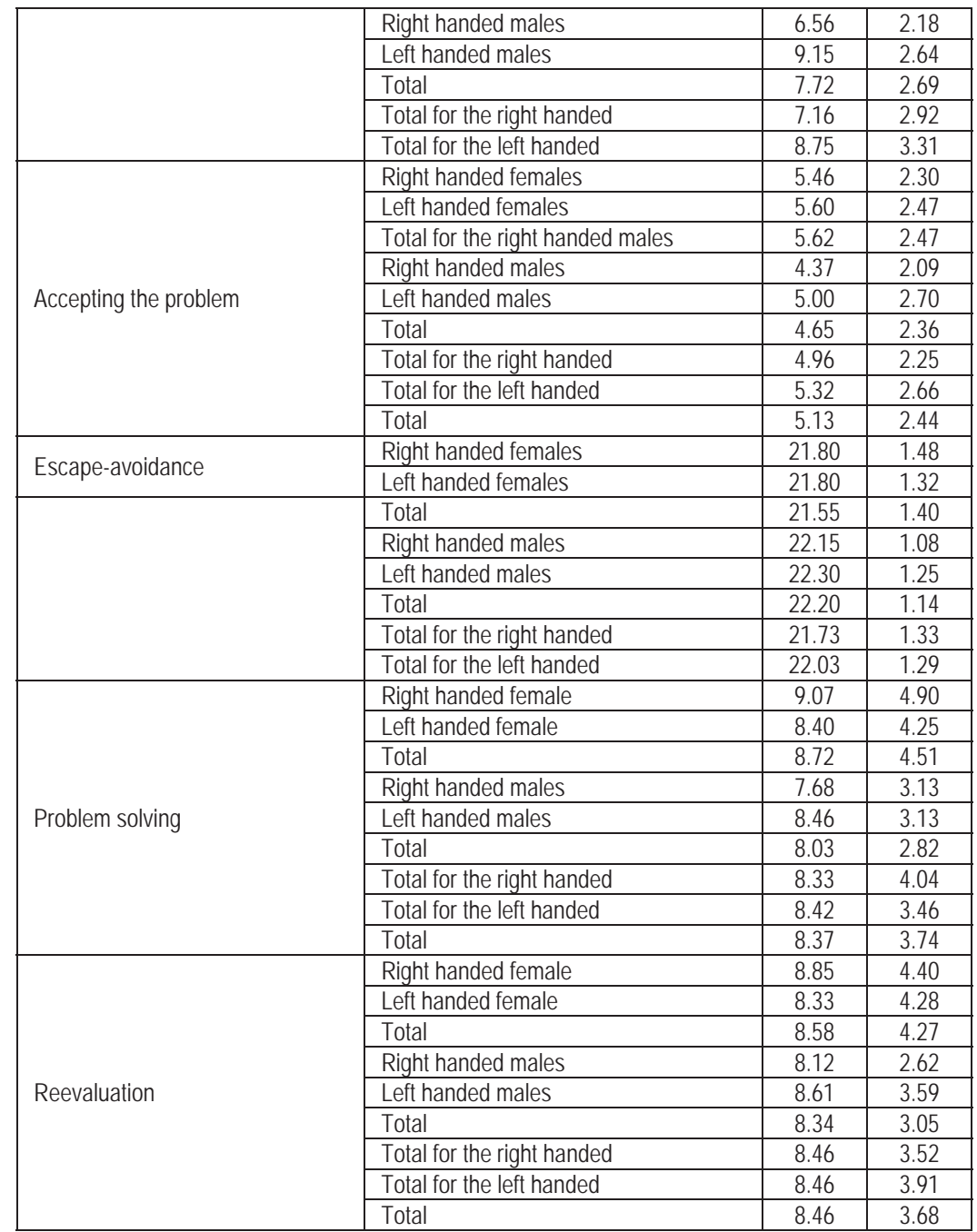

Concerning the data mentioned in the table 1 and 2, the use of quadratic multivariate test (Pilaei effect, Wilk's lambda, Halting's track and largest Roy's square) determines that there is a meaningful relation between the dependent variables (the coping strategies with stress) with an emphasis on gender and handedness $(P<0.01)$. Therefore, the conditional situation of MANOVA is possible.

Table.2. multivariate tests variance in order to investigate the dependent variables of "coping strategies " with an emphasis on "gender and handedness"

\begin{tabular}{|c|l|c|c|}
\hline Effect & Multivariate test & $\mathrm{F}$ & Significant level \\
\hline \multirow{4}{*}{ Levels } & Pilaei effect & 9256.19 & 0.00 \\
\cline { 2 - 4 } & Wilk's lambda & 9256.19 & 0.00 \\
\cline { 2 - 4 } & Halting's track & 9256.19 & 0.00 \\
\cline { 2 - 4 } & Largest Roy's square & 9256.19 & 0.00 \\
\hline
\end{tabular}


Table.3. the analysis of the findings of multivariate variance in order to Investigate the interactional effects of inter-group variables for coping Strategies with an emphasis on gender and handedness (MANOVA)

\begin{tabular}{|c|c|c|c|c|c|c|c|}
\hline Effect & Dependent variable & Square set & FD & Mean for squares & $\mathrm{F}$ & Sig. t level & Effect intensity \\
\hline \multirow{10}{*}{ Levels } & Emotion- focused & 215789.38 & 1 & 6604.75 & 6604.759 & 0.00 & 0.99 \\
\hline & Appraisal -focused & 57411.73 & 1 & 550.14 & 550.144 & 0.00 & 0.91 \\
\hline & Direct coping & 16667.05 & 1 & 22102.52 & 22102.52 & 0.0 & 0.99 \\
\hline & Distancing & 16.4538 & 1 & 18028.25 & 18028.25 & 0.0 & 0.99 \\
\hline & Self -control & 18373.93 & 1 & 10437.19 & 10437.19 & 0.0 & 0.99 \\
\hline & Seeking social support & 3683.73 & 1 & 376.07 & 376.073 & 0.0 & 0.87 \\
\hline & Accepting the problem & 1531.77 & 1 & 254.85 & 254.843 & 0.0 & 0.82 \\
\hline & Escape- avoidance & 27599.88 & 1 & 16601.17 & 16601.17 & 0.0 & 0.99 \\
\hline & Problem solving & 4073.01 & 1 & 280.11 & 280.11 & 0.0 & 0.83 \\
\hline & Reevaluation & 4148.56 & 1 & 291.74 & 291.74 & 0.0 & 0.84 \\
\hline \multirow{10}{*}{ Errors } & Emotion-focused & 1764.277 & 56 & 32.67 & & & \\
\hline & Appraisal- focused & 31.5635 & 56 & 104.35 & & & \\
\hline & Direct coping & 40.72 & 56 & 0.75 & & & \\
\hline & Distancing & 49.28 & 56 & 0.91 & & & \\
\hline & Self-control & 95.06 & 56 & 1.76 & & & \\
\hline & Seeking social support & 528.94 & 56 & 9.79 & & & \\
\hline & Accepting the problem & 324.56 & 56 & 6.01 & & & \\
\hline & Escape- avoidance & 89.77 & 56 & 1.66 & & & \\
\hline & Problem solving & 785.19 & 56 & 14.54 & & & \\
\hline & Reevaluation & 767.87 & 56 & 14.22 & & & \\
\hline \multirow{10}{*}{ Total } & Emotion-focused & 222588 & 58 & & & & \\
\hline & Appraisal focused & 64571 & 58 & & & & \\
\hline & Direct coping & 16804 & 58 & & & & \\
\hline & Distancing & 16579 & 58 & & & & \\
\hline & Self-control & 16637 & 58 & & & & \\
\hline & Seeking social support & 4230 & 58 & & & & \\
\hline & Accepting problem & 1872 & 58 & & & & \\
\hline & Escape- avoidance & 27863 & 58 & & & & \\
\hline & Problem solving & 4872 & 58 & & & & \\
\hline & reevaluation & 4929 & 58 & & & & \\
\hline
\end{tabular}

Concerning the amount of $\mathrm{F}$ resulting from the multivariate variance analysis model (ANOVA) in order to make a relation among the dependent variables (coping strategies with an emphasis on gender and handedness), it is showed that there is a meaningful relation among some of dependent and independent variables (level $\alpha=0 / 01$ ).

The data mentioned in the tables showed that the mean for the lefthanders' responses in emotion-focused coping strategies in both genders is less (the mean for the left handed females 62.26, the right handed females 62.85 and the left handed males 53.15 and the right handed males 66.43). In fact, the emotion-focused strategy is used less by the left handed. This relation is statistically significant. in the appraisal-focused coping strategy, the mean is higher for the left handed (the mean for the right handed females 31.14, the left handed females 38.93 , the right handed males 25.68 and the left handed males 30.4); that is, the appraisal-focused strategies are used by the left handed more than the right handed. This relation is statistically meaningful. In the direct coping strategy, the mean for the left handed is higher (the mean for the left handed females 17.13, the right handed females 16.78, the left handed males 17.15 and the right handed males 16.93) but this relation is not statistically meaningful. In distancing strategy, the mean for the right handed females with a little difference (mean 16.71) is higher than that for the left handed females (mean 16.60) but the mean for the left handed males is higher mean than that for the right handed ones (17.38vs.16.87) but this relation is not statistically significant. In self-control strategy, the mean for the left handed in both genders is higher; that is, self-control strategy is used more by these groups (the mean for left handed females 18.06, the right handed females 16, the left handed males 19.15 , and the right handed males 18.18) but this relation is not statistically significant. In seeking social support, the mean for the left handed in both genders is higher; that is, this strategy is used more by this group (the mean for the left-handed females 8.4, the right-handed females 7.85, the left-handed males 9.1 and the right-handed males 6.56). Moreover, this relation is statistically significant. In the accepting responsibility strategy, the mean for the 
lefthanders in both genders is higher; that is, the accepting responsibility strategy is used by this group (mean for the left handed females is 5.60, the right handed females 6.46, the left handed males 5, the right handed males 4.37). This relation is statistically meaningful. In the escape-avoidance strategy, in both groups (the left handers and right handers) and genders, no significant difference is observed (the mean for the left-handed females is 21.8 , the right handed females 21.8, the left handed males 22.1 and right handed males 22.3). In the problem solving strategy, the mean for the lefthanders in both genders is higher; that is, this group uses the problem solving strategy more than other groups (the mean for the left-handed females is 9 right, handed females 8.4, left handed males 8.4 and right handed males 7.68). In the reevaluation strategy, the mean for the left handed females (8.33) is a little higher than that for the right handed females (8.8) while the mean for the right-handed males (8.85) is a little higher than that for the left handed males (8.61). Of course, this relation is not statistically significant.

\section{Discussion and Conclusion}

The findings of the study shows that the appraisal-focused coping strategy is more used by left handed and emotionfocused strategy by the right handed more in both genders. Many studies emphasized the fact that the right hemisphere of the brain is closely related to the problem solving and discovery of way to solve the problem (Levi, 1974, Robert \& Bloom, 1997, Joanc, 1998). Furthermore, Edward and et al. (1998) investigated those group of people whose right hemisphere were injured. The results of their study illustrated that these individuals had more problems in solving the problem, analyzing and presenting the correct response. Of course, Michaell (2000) showed in his study that understanding and problem solving were closely related to the left hemisphere of brain. Referring to the data mentioned in the tables, it is demonstrated that the mean for the left handers responses in the emotion-focused coping strategies is less for both genders (the mean for the left handed females is 62.26 , right handed females 62.85 , left handed males 53.15 and right handed males 66.43). In fact, the emotion-focused coping strategies are used less by the left handers and this kind of relation is statistically significant. Silberman and Weingartner (1986) noted that the emotions were closely linked to the brain lateralization and the right hemisphere of brain was effective in controlling emotions and behavioral assignments related to emotions. In several studies, it was mentioned that positive emotions were lateralized in the left hemisphere and the negative emotions in the right hemisphere but what was important was that the content of emotions were evaluated in the right hemisphere. In the study by Perete (2014) who focused on emotions and their control, it is displayed that priority of right hemisphere in evaluating and controlling emotions. This finding was confirmed in both brain injured and healthful subjects. In the direct coping strategy, the mean for the left handers is higher (the mean for the left handed females is 17.3 , right handed females 16.78, left handed males 17.5 and the right handed males 16.93) but this relation is not statistically significant. In distancing strategies, the mean for the right handed females (16.71) is a little higher than that in left handed females (16.60) but the mean for the left handed males is a little higher than that the right handed males (17.38 vs.16.87). In the self-control strategies, the mean for the left handers in both genders is higher; that is, self-control strategy is used more by this group (the mean for the left handed females 18.06, right handed females 16, the left handed males 19.15 and the right handed males 18.18) but this relation is not statically significant. In seeking for social support, the mean for the left handers in both genders is higher; that is, this strategy is used more by this group (the mean for the left handed females is 8.4, the right handed females 7.85, the left handed males 9.1 and the right handed males 6.56). In addition, this relation is statistically significant. The results of a study by Edward and et al. (1998) showed that more activities at the right hemisphere of brain was followed by better understanding of nonverbal rules and symbols. He illustrated in his study that the stronger people were in the right hemisphere, the easier it would be to follow interactions and asking for help from others.

In accepting responsibility strategy, the mean for the left handers are higher in two genders; that is, this strategy is used more by this group ( the mean for left handed females is 5.60 , the right handed females 6.46 , the left handed males 5 and the right handed males 4.37). This relation is statistically significant. Edward and et al. (1998) found in their study that those individuals with some injury on the right hemisphere had many problems in knowing, solving problem, observing and accepting the problems. In the escape-avoidance strategy, no much difference was observed in both genders (the mean for the left handed females is 21.8, the right handed females 21.8, the left handed males 22.1 and the right handed males 22.3). This relation is not statistically significant. In the study by Spielberger et al. (2011), who investigated the avoidance responses by the use of a questionnaire, knew avoidance was closely related to the lateralization in the left hemisphere of brain but he showed in his study that theories showed that avoidance was closely related to the lateralization at the right hemisphere of brain. In reevaluation strategy, the mean for the left handed females (8.33) is a little higher than the right handed females (8.8) while the mean for the right handed males (8.85) is a little higher than that for the left handed males (8.61). Of course, this relation is not statistically significant. Certainly, several 
factors such as intelligence, culture, could be effective in doing psychological procedures but some of these factors such as accepting the problem could not be effective (Edward and et al., 1998).

In the educational environments like school, teachers can use the students' whole features and capacities in order to know and understanding their abilities. One of these features to which students also notice is handedness. As it is observed the appraisal focused strategies are used more by the left handed students who are in minority while emotionfocused strategies are used more by the right handed students. Teachers and mentors can use the finding of this study practically in order to know students, doing extracurricular programs, putting responsibilities on students' shoulders and even choosing major. It is suggested to the researchers to investigate the relation between the teachers' handedness and teaching methods, their individual features and especially the way they behave with the left handed students.

\section{References}

Smart. J, D, Rolston b, Charles. M, Epstein.C. R. E, Gross. T, sato. Y, utswmi. K (2012). Psychiatry Research .187. 354-362.

Bibbey, A., Carroll, A., Roseboom, B. C., Phillips, C. A., \& Susanne, R. E. (2013). International Journal of Psychophysiology, 90, 28-36.

Bouetr, P. (2012). Coping with stress, coping with valence: links to mental health outcomes among at-risk youth. Journal of Psychopathology and Behavior Assessment, 34(3), 405-414.

Carlson, J. N. (1993). Lateralization change in prefrontal cortical dopamine activity induced by controllable and uncontrollable stress in the rat. Brain Research, 630(1-3), 178-187.

Castor, L. scilo, A. \& paniel, W. K. (2010). Gender differences in the relationship between emotional intelligence ad right hemisphere lateralization for facial processing. .behavioral brain research.

Edward, M. Bowden, G. \& markjung, B. (1998). Getting right idea: semantic activation in the right hemisphere may help solve insight problems. Psychological scince, 9(6)435-440

Hashimoto, T. \& Yamazak, Y. Asushi, I. (2013). Hand preference depends on posture in common marmosets .behavioral brain research, 248,144-150.

Levy, J. (1974). Cerebral asymmetries as manifested in split-brain man .In M. kinsbournce \& W.L. SMITH (Eds.), hemispheric disconnection and cerebral function. Springfield, IL: Charles C. Thomas.

Joanc, B. (1998). Right hemisphere emotional perception. American psychological association .12(3).446-455.

Michael, S. G. (2000). BRAIN BOOK. First published online.

Netlle, D. (2003). Hand laterality and cognitive ability: A multiple regression approach. Brain and cognition, 52(3), 390-398.

Nickolas, A. B., hill, C., Holden, A. \& Bishop, V. M. (2012). Do pOSCCl: A function transcrainal Doppler ultrasonography

Porac, C, Searleman, A. (2003). The effects of hand preference side and hand preference switch history on measures of psychological and physical well-being and cognitive performance in a sample of older adult right-and left-handers .Neuropsychological,. 40(12), 2074-2083

Robert, D., Bloom. D. M. (1997).selective lateralization of cognitive style recatied to occvpation as determind by EEG apha asymmetry. Psychophysiology, 4(4), 385-387.

Smokler IA, Shevrin H. (1979). Cerebral Lateralization and Personality Style. Arch Gen Psychiatry. 1979; 36(92014 American Medical Association JAMA the Journal of the American Medical Association - Hysterical and obsessive-ompulsive style subjects, as determined by a modified Rorschach test and the Wechslar Adult

Silberman, E. K., Weingartner, H. (1986). Hemispheric lateralization of function releted to emotion. Psychopatology.59 (5). $322-353$.

Spielberger, S.A., Sutton, B.P., Banich, M.T. \& Teller, W. (2011).trait approach and avoidance motivation lateralized neural activity associated with executive function .54(1)661-670.

Spielberger. J, M, Miller, G.A., Engels, S. A. Sutton, B.P. \& Baich, M.T. (2011). Trait approach and avoidance motivation lateralized neural activity associated with executive function. 54(1), 661-670.

Mihor, M. Denzle, M. \& Foresten, J. (2010). Brain and cognition, 72(3), 442-448.

Sullivan, R.M. \& Gratton, A. (1998). Relationships between stress-induced increases in medical profrontal cortirical dopamin and plasma conticos levels in vats: role of cerebral terone laterality. Neuroscience. 83 (1), 81-91. PMID: 9466400 